\title{
MAQUETES DE ROMA: ENTRE HISTÓRIA E REPRESENTAÇÕES
}

Ivan Esperança Rocha1

\begin{abstract}
Resumo
Considerada uma arte milenar, a construção de maquetes ganha nas últimas décadas um impulso especial dado pelo uso de suportes eletrônicos tanto na área da arqueologia como da arquitetura e engenharia. Neste texto será apresentado e discutido o papel original e atual das maquetes na reconstrução histórico-arquitetônica da cidade de Roma, com destaque para aquelas criadas, nas primeiras décadas do século XX, por Giuseppe Marcelliani, Paul Bigot e Italo Gismondi.
\end{abstract}

\section{Palavras-chave}

Maquete; arqueologia; arquitetura, história; poder; museologia.

\begin{abstract}
Considered a millenarian art, the construction of models has gained in the last decades a special impulse using electronic supports in the area of archeology as well of architecture and engineering. In this text, will be presented and discussed the original and current role of the models in the historical-architectural reconstruction of the city of Rome, especially those created in the first decades of the 20th century by Giuseppe Marcelliani, Paul Bigot and Italo Gismondi.
\end{abstract}

\section{Keywords}

Model; archeology; architecture; history; power; museology.

\footnotetext{
1 Professor Livre Docente, Universidade Estadual Paulista, Assis, Brasil. E-mail: ierocha@uol.com.br
} 
A maquete ${ }^{2}$ é considerada uma arte milenar de reproduzir ou construir, em escala reduzida, os mais diferentes tipos de objetos, dentre eles estátuas, imagens votivas, edifícios privados e públicos, individualmente ou em conjuntos, armamentos, cenários do quotidiano, topografias e, inclusive, cidades inteiras. Nas últimas décadas, as maquetes físicas elaboradas em madeira, argila ou papel, passaram a contar com o novo suporte da virtualização eletrônica que facilitou não apenas a elaboração, mas também as atualizações e aperfeiçoamento dos projetos de miniaturização ${ }^{3}$.

Assim, se notamos na utilização de maquetes no passado limites impostos pela técnica de elaboração e pela extensão de seu uso, o surgimento nas últimas décadas de tecnologias físicas e eletrônicas estimularam o seu uso em larga escala para apresentação e divulgação de empreendimentos imobiliários e de produtos lançados ou a serem lançados no mercado, planos de urbanização e também para ensaios sobre diferentes característica do objeto miniaturizado - seja ele um edifício, um veículo, uma aeronave - como sua capacidade de resistência a choques, intempéries, tremores de terra, e inclusive maremotos, tendo em vista a segurança individual e coletiva.

As maquetes arquitetônicas, originalmente desenvolvidas por artesãos, passaram a constituir parte integrante da formação e do trabalho, particularmente, de engenheiros e arquitetos. A arquitetura e a engenharia contemporâneas se interessam, inclusive, pela história das maquetes ao longo do tempo, desde suas primeiras aparições na Antiguidade, como se verifica no estudo de Rozestraten sobre as maquetes de Tepe Gawra, na Mesopotâmia (ca. 3500 a.C.), de Dashur, no Egito (1900-1730 a.C.), de Arkhanes, Grécia (1700-1630 a.C.) (figura 1), do templo de Niha (séc. II d.C.) e do teatro de Baalbek (séc. II d.C.), no Vale de Becaa, e de Ostia (sec. I a.C.) e do stadium de Villa Adriana, na Roma Antiga (séc. II d.C.) ${ }^{4}$.

\footnotetext{
2 Maquete provém da palavra italiana macchieta (esboço) pelo francês maquette (Houaiss, A. Dicionário Eletrônico Houaiss. Rio de Janeiro: Objetiva, versão 1.0.1 [CD $\mathrm{ROM}], 2001)$.

${ }^{3}$ Royo, Manuel. Une nouveauté du xxe siècle? Maquettes de Rome et perception " paysagère » de l'histoire. Histoire de l'art, n. 65, out 2009, p. 7.

4 Roszestraten, Artur Simões. Estudo sobre a história dos modelos arquitetônicos na Antiguidade: origem e características das primeiras maquetes de arquiteto. São Paulo: USP, 2003. 285p. Dissertação (Mestrado em Arquitetura e Urbanismo). Faculdade de Arquitetura e Urbanismo, Universidade de São Paulo, p. I-II.
} 


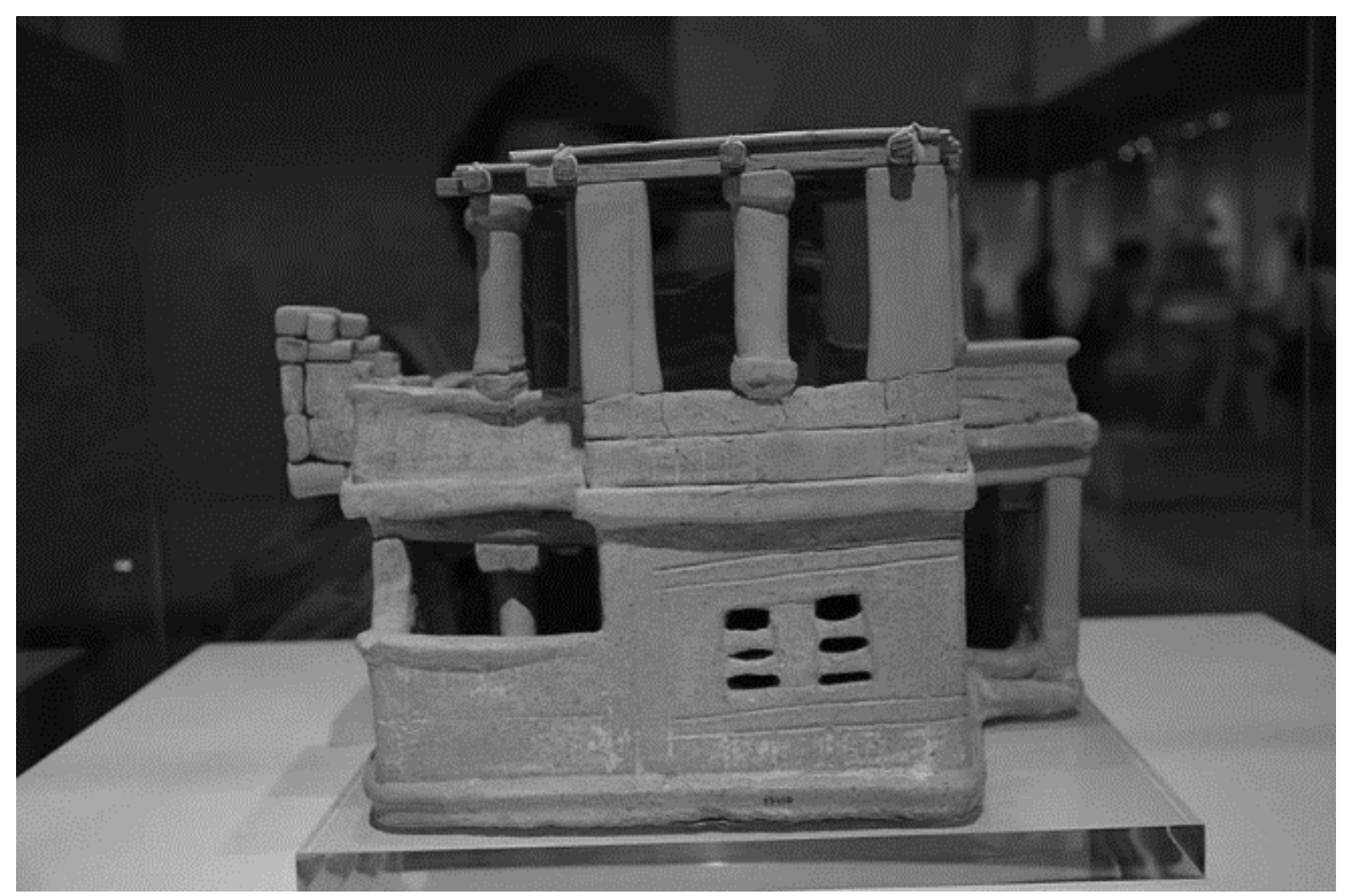

Fig. 1. Maquete de uma casa. Arkhanes. Heraklion Archaeological Museum. Grécia.

Num trabalho conjunto, historiadores e arquitetos se debruçaram na elaboração de maquetes de cidades de diferentes tempos e espaços. Temos maquetes totais ou parciais de Jerusalém, Beersheva, Atenas, Meca, Éfeso, Mileto, Mérida, Londres, Bruxelas, Viena, Nova Yorque, Detroit, São Francisco, Dubai, Sidney, Shangai, Brasília, dentre tantas outras. Há também maquetes de cidades inteligentes idealizadas, como Iskandar na Malásia 5 .

Neste texto será apresentado e discutido o papel das maquetes na reconstrução histórico-arquitetônica da cidade de Roma, explicitando a proximidade que se estabelece entre história e arquitetura na sua criação. As maquetes urbanas da cidade de Roma constituem uma característica do século XX e elas incorporam o patrimônio gráfico e artístico reunido entre os séculos XVII e XVIII, que inclui a tradição da cenografia teatral e da pintura histórica ${ }^{6}$.

Essas obras são inicialmente realizadas por artesãos e representam construções em ruínas e não restauradas que alimentaram as coleções de

\footnotetext{
5 Iskandar Malaysia: City Of The Future. Disponível em: $<<$

http://lankasia.com/content/iskandar-malaysia-city-future>>. Acesso em 25 outubro 2017.

${ }^{6}$ Royo, Manuel, op.cit., p. 7.
} 
antiquários como John Soane e de aristocratas como Frederico Francisco I de Mecklemburgo, Catarina II da Rússia e Gustavo III da Suécia7. Deve-se dizer que os pintores que se envolveram, na Idade Média, com representações arquitetônicas do passado trabalharam a partir de modelos que eles jamais viram, buscando inspiração nas fontes documentais disponíveis e na tradição oral, mas distante ainda das contribuições que seriam oferecidas pela arqueologia ${ }^{8}$.

Sobre a cidade de Roma, existem três grandes maquetes históricas: a do escultor italiano Giuseppe Marcelliani, realizada entre 1905 e 1906, na escala 1:100, a do arquiteto francês Paul Bigot, com uma dimensão de 70 $\mathrm{mt}^{2}$, na escala de 1:400, realizada entre 1906 e 1911, conservada na Universidade de Caen (figura 4), e a do arqueólogo italiano Italo Gismondi, na escala de 1:250, que representa a cidade no período de Constantino, do início do IV século d.C., construída entre 1933 e 19379 e conservada no Museo della Civiltà Romana, em Roma ${ }^{10}$ (figura 3).

As maquetes de Giuseppe Marcelliani (figura 2) e Paul Bigot se situam em um momento em que Roma ganha uma grande visibilidade por ter passado, em 1871, de capital dos Estados Pontifícios para, depois de Turim e Florença, tornar-se capital do reino da Itália unificado sob a liderança de Giuseppe Garibaldi.

A maquete de Italo Gismondi, que teve a colaboração de Guglielmo Gatti, Antonio Maria Colini e Paolo Fidenzoni tornou-se uma peça importante na grande exposição organizada por Mussolini com o propósito de restaurar o antigo prestígio de Roma na comemoração dos dois milênios de nascimento do imperador Augusto (1937), tendo sido instalada no Palazzo delle Esposizioni ${ }^{11}$. A maquete cria uma ideia de Roma pulitta, por eliminar os enclaves produzidos na modernidade, reconduzindo-a a

\footnotetext{
7 Royo, Manuel, op. cit., p. 8.

8 Carpo, Mario. How to you imitate a building that you have never seen? Printed images, Ancient Models. Zeitschrift für Kunstgeschichte, 64 bd, h. 2, 2001, p. 224.

${ }_{9}$ Italo Gismondi continuou a trabalhar nesta maquete até 1971.

10 Tais maquetes possuem uma estrutura modular e receberam alterações de seus autores: a de G. Marcelliani, de 1904 a 1910, a de Paul Bigot, de 1904 a 1942 e a de Italo Gismondi, de 1937 a 1973. O Museo dela Civiltà Romana encontra-se, atualmente, fechado para reforma (Constantini, Valeria. Museo della Civiltà Romana assediato da rave party e rifiuti. Corriere della Sera. Edição de Roma, 9 agosto 2017). Avalia-se pouco adequado e acolhedor o espaço em que se encontra a maquete nesse Museu (Pasqualini, Anna. L'antiquaria di gesso: passato e futuro del Museo della Civiltà romana all'Eur. Mediterraneo Antico, v. ix, n. 2, 2006, p. 9.

11 Pedro Paulo Funari discute as possíveis relações entre arqueologia e poder (Arqueologia. São Paulo: Contexto, 2003, p. 69-75).
} 
sua originalidade. Naquele momento, a única maquete com uma reconstrução de Roma era a, já citada, de Giuseppe Marcelliani, que no momento se encontrava desmontada ${ }^{12}$.

A maquete original de Gismondi passou por várias modificações realizadas por seu próprio autor, mas defende-se que algumas de suas seções precisam passar por mudanças radicais 13 , mudanças essas que podem ser facilitadas atualmente por meio dos recursos eletrônicos disponíveis.

Várias exposições foram organizadas em torno do tema arquitetura e maquetes, com contribuições diretas e indiretas de inúmeros pesquisadores e que foram registradas em publicações. Lambert dá destaque a duas delas por sua importância: a primeira, realizada em 1994, em Veneza (levada depois para Washington, Paris e Berlim), que consagrou grandes nomes de Brunelleschi a Miquelângelo; a segunda, em 1997, em Turim (levada depois para Montreal, Washington e Marselha) celebrando os períodos barroco e clássico, tendo sido dado um lugar de destaque para as maquetes na atividade dos arquitetos ${ }^{14}$. Em relação a esses congressos, Lambert destaca um deles que teve por tema "As maquetes arquitetônicas, função e evolução de um instrumento de criação e realização", em que se afirma a importância do papel das maquetes na arquitetura. Nele os autores discorreram, dentre outros temas, sobre os modelos arquitetônicos e projetos da antiguidade (Alessando Pierattini); função e evolução das maquetes (Christoph Luitpold Frommel); maquetes arquitetônicas na Alemanha durante o Renascimento (Stefan Hoppe); maquetes arquitetônicas na Espanha durante e após o Renascimento (Pedro Antonio Galera Andreu); maquetes nos Países Baixos entre 1500-1700 (Marlijn Hurx \& Konrad Ottenheym); o túmulo de Rousseau no Panteão como maquete arquitetônica do templo vitruviano (Eleonora Guzzo); a razão da emergência da maquetes sob o Império (Jean-Michel Leniaud); aproximações entre o desenho e a maquete

${ }^{12}$ Royo, Manuel, op. cit., p.10-14. LIBERATI, Anna Maria. La rappresentazione di Roma antica nel plastico di Gismondi del Museo della Civilà Romana a Roma. Cahier de la MRSH, n. 33, junho 2003, p. 243-44. ELLIS, D.B. Eternal city. Greece E Rome, v. 6, n. 2, 1999, p. 191.

${ }^{13}$ Libertati, Anna Maria, op. cit., p. 248.

${ }^{14}$ Lambert, Guy. Le maquettes d'architecture. Publications récents. État de la récherche. Archiscopie, 2e série, 2016, p. 94. 
(Benjamin Mouton); o papel da maquete na reconstrução (Clemens Knobling) ${ }^{15}$.

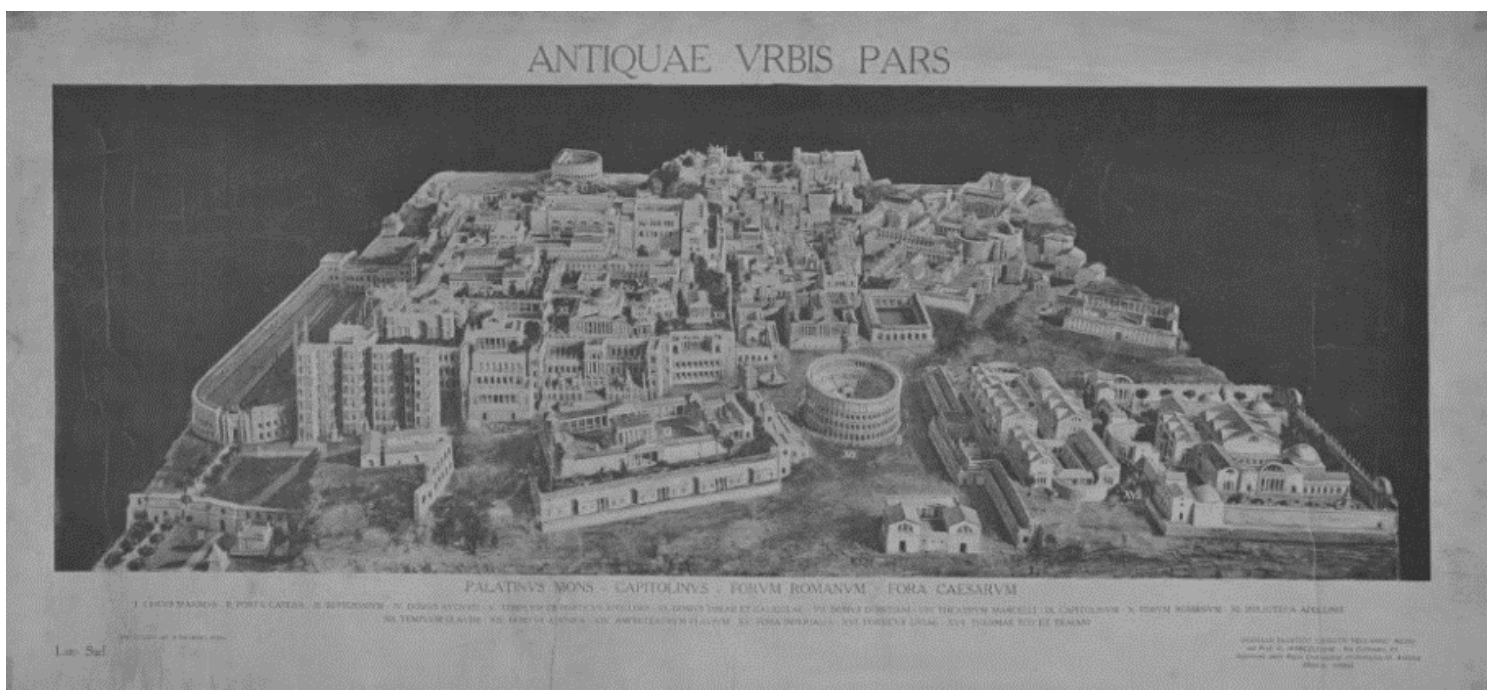

Fig. 2. Maquete de Roma, de Giuseppe Marcelliani, 1905 e 1906. Museo della Civiltà Romana.

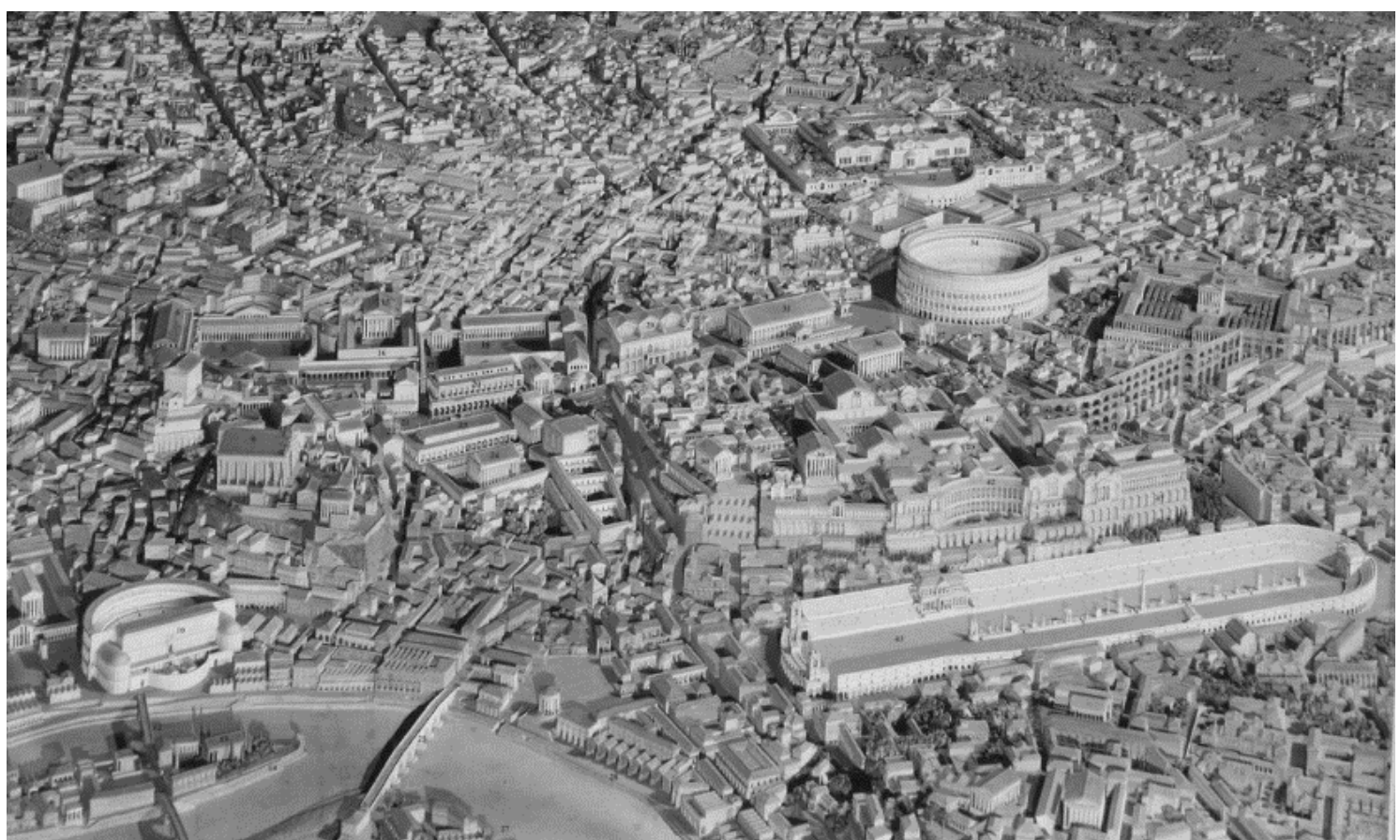

Fig. 3. Maquete de Roma de Italo Gismondi, 1933 e 1937. Museo dela Civiltà Romana.

${ }^{15}$ Lambert, Guy,op.cit., p. 91-96, 2016; Fromm, Sabine. Les maquettes d'architecture: fonction et évolution d'un instrument de conception et de réalisation. Paris: Picard; Roma: Campisano Editore, 2015, p. 1-11. 


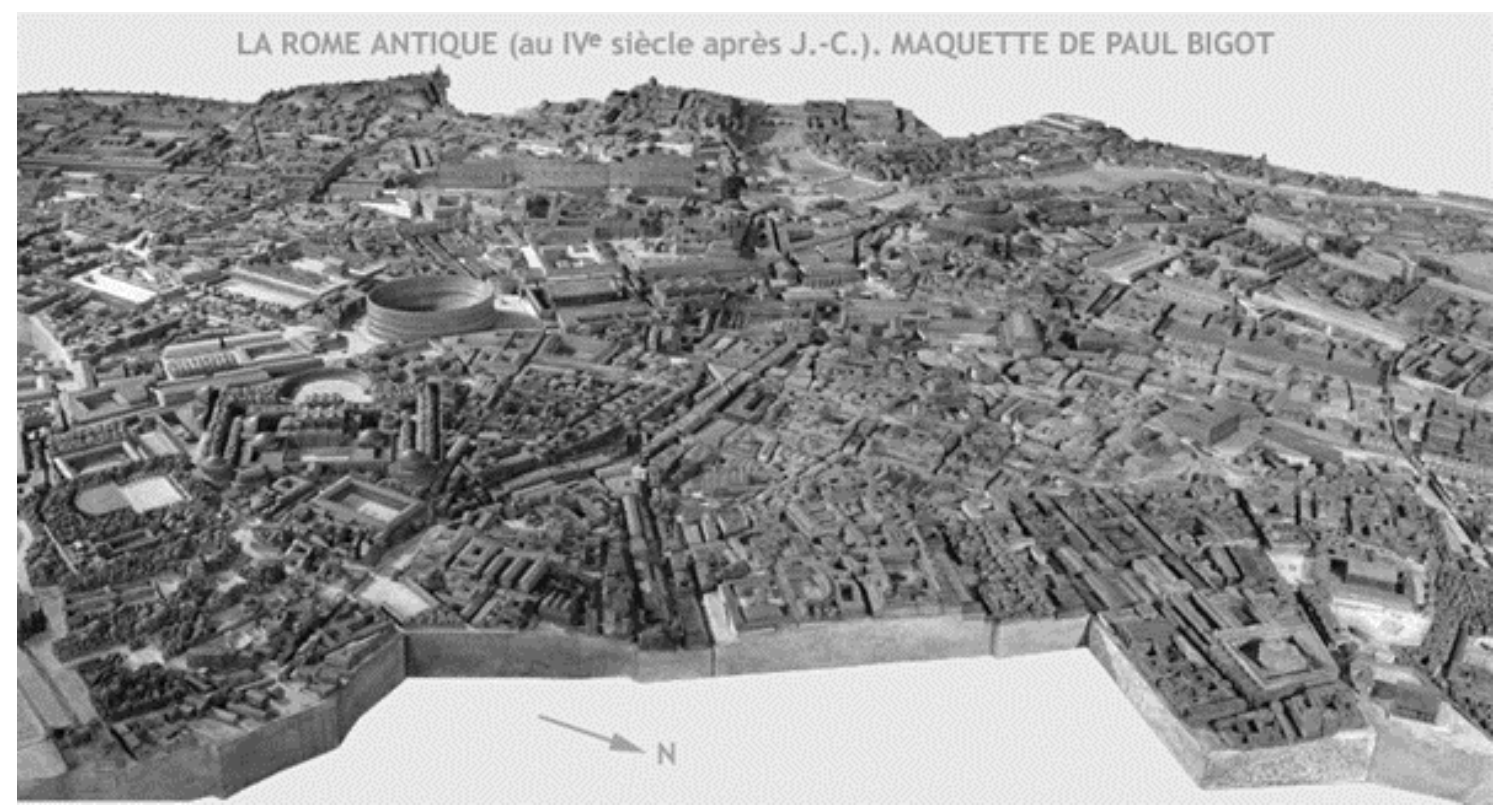

Fig. 4. Maquete de Roma Paul Bigot, 1906-1911. Universidade de Caen, França.

Esta é apenas uma amostragem da efervescência de pesquisas em torno das maquetes em sua relação com a arquitetura, com a história e com a cultura em geral.

Uma das questões discutidas nesses textos foi o surgimento de profissionais especializados na construção de maquetes para suprir a formação deficitária de arquitetos nesse setor, e uma dúvida de que, diante de um crescimento exponencial de meios de concepção e de representação, a maquete física pudesse, eventualmente, ter perdido seu lugar, não obstante o grande potencial de criatividade a ser investido na sua criação ${ }^{16}$.

Se as maquetes podem ser encontradas já na antiguidade, nem sempre podem ser consideradas como protótipos de uma construção, podendo desempenhar outros papeis como o de ofertas votivas, como no caso de divindades ou templos em escala reduzida ${ }^{17}$. Com relação à maquete de estádio da Villa Adriana, do séc. II d.C., embora esta villa tenha sido construída pelo imperador Adriano com os confortos de uma cidade, com seus palácios, teatros e jardins, não há sinais da presença de um estádio no local, como poderia indicar a maquete de um estádio ali encontrada. Além, disso, com exceção do estádio de Domiciano construído no Campo de Marte, em Roma, os outros exemplares conhecidos de estádios romanos se localizam na Grécia, na Ásia Menor e no Oriente Próximo.

${ }^{16}$ Lambert, , Guy, op.cit., p. 95.

17 Maligorne, Y., Chevet, P., Ferrette, R. Deux maquettes architecturales récemment découvertes à Rennes. Latomus, n. 69, 2010, p. 99.117. 
A respeito da maquete de Gismondi, a base topográfica utilizada em sua realização foi quanto restava da Forma Vrbis Seueriana, um grande mapa esculpido em mármore, do tempo de Setímio Severo (145-211 d.C.). Foi utilizada também a Forma Vrbis Romae de Rodolfo Lanciani, elaborada entre 1893 e 1901, e que constituía uma síntese das antigas e novas descobertas ocorridas em fins do Oitocentos, por ocasião dos trabalhos efetuados no momento em que Roma foi definida como capital do reino da Itália em que foram levantados novos dados topográficos durante as demolições efetuadas pelo regime fascista, tendo em vista o isolamento do espaço dos monumentos augustinos, entre os quais se destacava a Ara Pacis. Para a reconstituição de construções residenciais, Gismondi utilizou informações obtidas em suas escavações em Ostia, localizada nas imediações de Roma ${ }^{18}$. Muitas mudanças precisam ser feitas na maquete a partir de novas descobertas em diferentes áreas da cidade, como nos Foros Imperiais, no entanto, devido aos altos custos das modificações, sugeriu-se que elas possam ser feitas com recursos eletrônicos mais modernos e práticos ${ }^{19}$, como vem ocorrendo com a maquete de Bigot em Caen, na França.

Em relação à virtualização de maquetes de Roma, destacam-se atualmente dois projetos. Um primeiro, o projeto da Universidade de Caien, França ${ }^{20}$, iniciado a partir de 1994, baseado na maquete que Paul Bigot (figura 5) constrói entre 1906-1911 e que ele tinha se proposto a atualizar no final da década de 1930, utilizando novas informações da arqueologia, mas o que não foi possível ser realizado devido à Segunda Guerra Mundial e à sua morte em 8 de junho de 194221, ao qual se somaria o projeto internacional Rome Reborn com o mesmo objetivo, desenvolvido pela Universidade da Virginia, EUA, a partir de 1997. Em ambos os casos, há uma preocupação em atualizar a maquete de Bigot utilizando novas informações da arqueologia 22 .

\footnotetext{
18 Liberati, Anna Maria, op. cit, p. 244-246.

19 Idem, p. 248-250.

20 Diversamente do que acontece, atualmente, com a maquete de Italo Gismondi, a maquete de Caen, graças à política de valorização da obra atrai muitas visitas e é objeto de estudos e congressos (Pasqualini, Anna, op.cit., p. 6, nota 23).

21 Paul Bigot: un normande à Rome. Disponível em: $<<$ https://www.unicaen.fr/cireve/rome/pdr_maquette .php?fichier=bigot $>>$. Acesso em 26 outubro 2017.

22 Isto se deve ao fato de ocorrerem permanentes mudanças nas evidências da arqueologia (Funari, Pedro P. Arqueologia. São Paulo: Contexto, 2003. Resenhado por Orser Jr, Charles E. Mneme, v.6, n.13, dez/2014-jan 2005, p. 98), ou seja, a arqueologia deve ser interpretada como uma ciência em construção (Funari, Pedro P. Arqueologia. São Paulo: Contexto, 2003, p.9)
} 


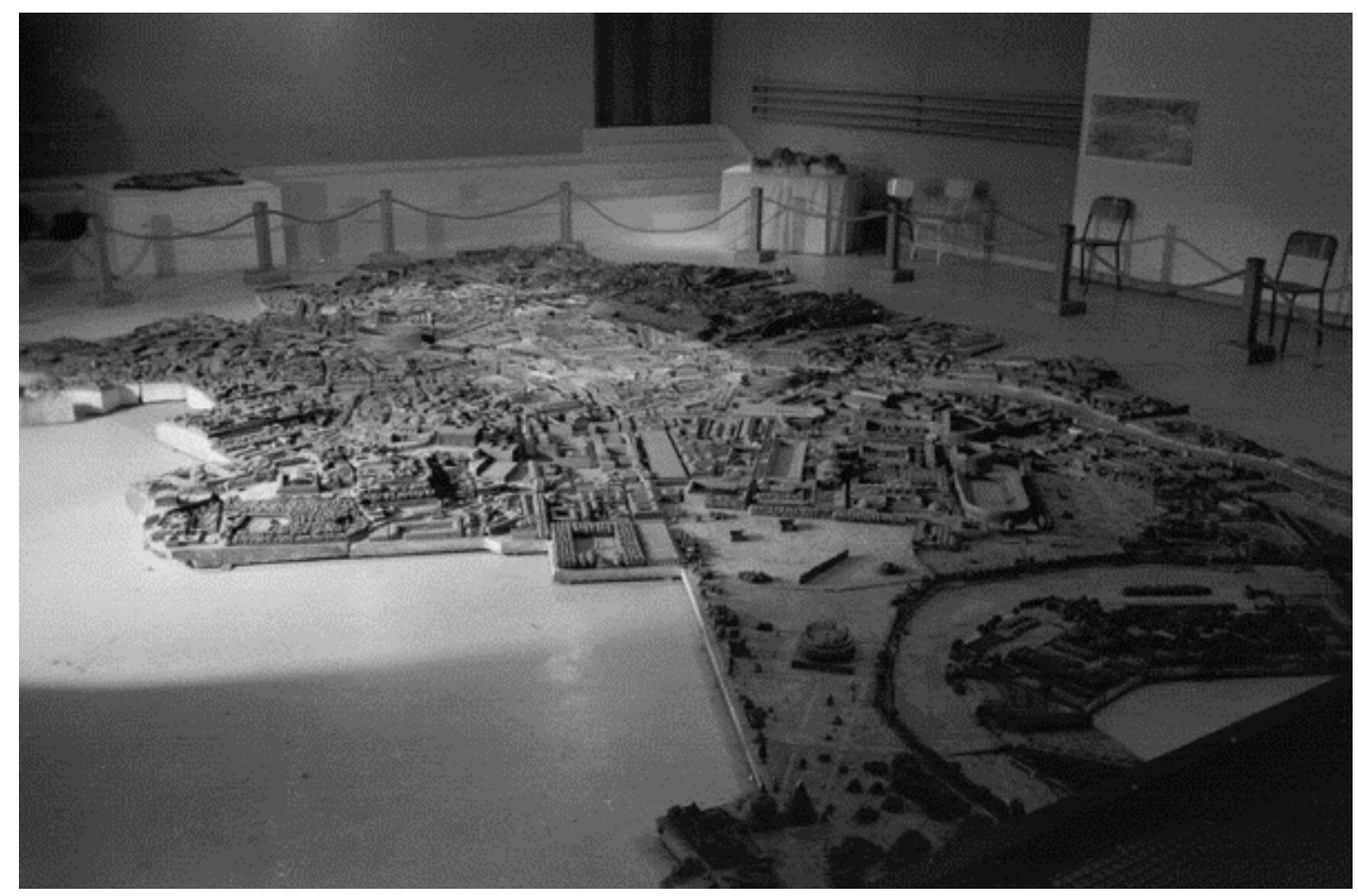

Fig. 5. Maquete de Roma Paul Bigot, 1906-1911. Universidade de Caen, França.

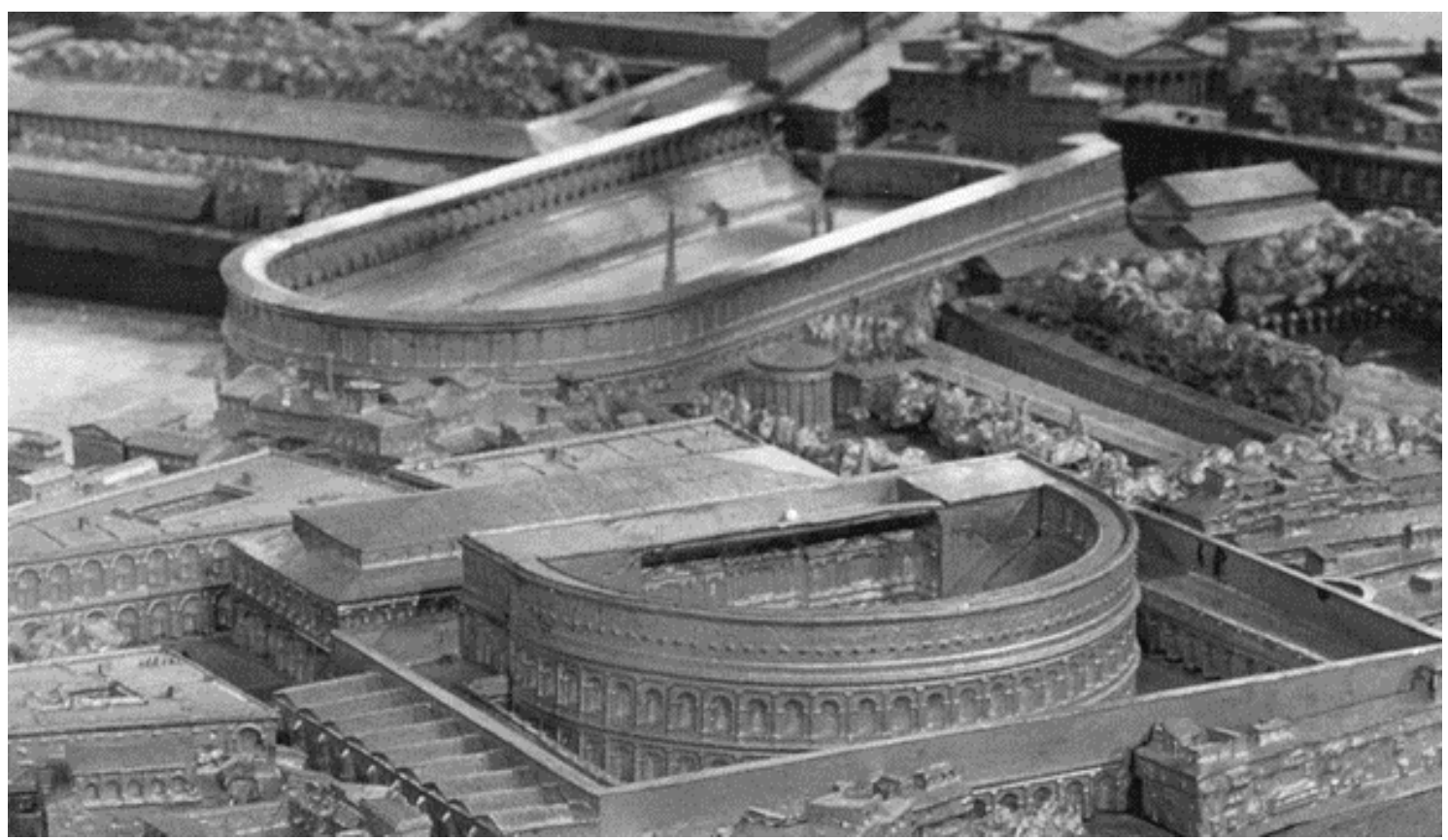

Fig. 6. O teatro de Balbus e o Circo Flamínio na maquete parcial em bronze de Paul Bigot. Universidade de Caen, França 
O projeto de Caien busca criar uma maquete virtual interativa de toda a cidade de Roma, propondo uma reconstituição de espaços exteriores (ruas, casas, lojas, monumentos públicos, redes de abastecimento de água, etc) e uma parte de espaços interiores (particularmente edifícios públicos mais populares, e alguns exemplares de moradias e áreas de comércio). Também são reconstituídos sistemas de elevação de água, moinhos de água, instrumentos de medição, máquinas de guerra. As fontes textuais, arqueológicas e iconográficas utilizadas na construção da maquete também podem acessadas virtualmente ${ }^{23}$.

A metodologia utilizada incluiu informações sobre cada tipo de construção disponível em todos os textos em latim e grego, assim como na epigrafia. Para a modelagem do Teatro de Pompeu, foram utilizados 93 textos latinos e 18 textos gregos. A análise das fontes contou com a colaboração de estudiosos sobre literatura greco-romana, historiadores da antiguidade, arqueólogos e arquitetos, com seus representantes incluídos no comitê de monitoramento e validação do trabalho ${ }^{24}$.

Em relação ao projeto Rome Reborn, há uma ampliação em termos da datação dos monumentos reconstruídos: pretende cobrir o período de 1000 a.C. ao início do período medieval. O projeto inclui dois tipos de reconstruções: um que se refere a um número limitado de edifícios sobre os quais há informações detalhadas e outro que se refere a, aproximadamente, 6750 edifícios sobre os quais há pouca informação. $\mathrm{O}$ principal software utilizado para a virtualização dos monumentos é o CityEngine que permite diferentes tipos de visualização e de detalhamento das maquetes, complementado por outros recursos de criação de realidade virtual ${ }^{25}$.

Em conclusão, podemos dizer que as maquetes de Roma, em particular a de Paul de Bigot, que inspirou os projetos da Universidade de Caien e da Universidade da Virginia, e que ao incorporarem dinamicamente informações provenientes das descobertas arqueológicas, tornam-se um

23 Fleury, Philippe. Le Plan de Rome de Paul Bigot. De la maquette en plâtre de Paul Bigot à la maquette virtuelle de l'Université de Caen. Civiltà Romana, v. 1, 2014, p 118119. Atualmente existem dois exemplares físicos dessa maquete, o original se encontra em Caien e uma cópia, com intervenções a cores, nos Museus Reais de Arte e História de Bruxelas, além um projeto parcial em bronze que se encontra no Instituto de Arte e de Arqueologia de Paris (figura 6).

24 Fleury, Philippe, Maeleine, Sophie. L'accès aux sources anciennes sur le modèle virtuel de la Rome antique. Schaedae, n. 22, fasc. 3, 2009, p. 8.

${ }^{25}$ Dylla, Kimberly et al. Rome Reborn 2.0: A Case Study of Virtual City Reconstruction Using Procedural Modeling Techniques Charlottesville: Universidade da Virginia. Disponível em: <<http:/ / romereborn.virginia.edu>> Acesso em 26 outubro 2017. 
importante suporte pedagógico para o estudo da sociedade romana e suas estruturas urbanas do período a que se referem. Elas criam uma visão de conjunto da arquitetura da cidade de Roma que dificilmente poderia ser vislumbrada na observação isolada e parcial das ruínas de alguns de seus edifícios. Por mais hipotéticas que sejam algumas das reconstruções da maquete de Bigot, o fato de poderem ser continuamente atualizadas nesses dois projetos - que tendem a se multiplicar - por meio dos recursos eletrônicos disponíveis evitam os estereótipos comuns das maquetes físicas de Roma de Marcelliani e Gismondi.

\section{Bibliografia}

CARPO, Mario. How to you imitate a building that you have never seen? Printed images, Ancient Models. Zeitschrift für Kunstgeschichte, 64 bd, h. 2, 2001, p. 223-233.

CHENNAOUI, Youcef, JUAN-VIDAL, Francisco, FANTINI, Filippo. Architectural models and urban planning From Hadrian's Villa maquette to the amphitheater of Caesarea of Mauretania. In: INTERNATIONAL CONFERENCE ON CULTURAL HERITAGE AND NEWS TECHNOLOGIES, 2012, Viena. Anais... Viena: Museen der Stadt Wien, 2102, p. 1-19.

COSTANTINI, Valeria. Museo della Civiltà Romana assediato da rave party e rifiuti. Corriere della Sera. Edição de Roma, 9 agosto 2017.

DYLLA, Kimberly et al. Rome Reborn 2.0: A Case Study of Virtual City Reconstruction Using Procedural Modeling Techniques Charlottesville: Universidade da Virginia. Disponível em: <<http://romereborn.virginia.edu >> Acesso em 26 outubro 2017.

ELLIS, D.B. Eternal city. Greece \& Rome, v. 6, n. 2, 1999, p. 189-192.

FLEURY, Philippe, MADELEINE, Sophie. L'accès aux sources anciennes sur le modèle virtuel de la Rome antique. Schaedae, n. 22, fasc. 3, p. 4-18, 2009.

FLEURY, Philippe. Le Plan de Rome de Paul Bigot. De la maquette en plâtre de Paul Bigot à la maquette virtuelle de l'Université de Caen. Civiltà Romana, v. 1, 2014, p 109-124. 
FROMM, Sabine. Les maquettes d'architecture: fonction et évolution d'un instrument de conception et de réalisation. Paris: Picard; Roma: Campisano Editore, 2015, p. 1-11.

FUNARI, Pedro P. Arqueologia. São Paulo: Contexto, 2003.

FUNARI, Pedro P. Arqueologia. São Paulo: Contexto, 2003. Resenhado por ORSER JR, Charles E. Mneme, v.6, n.13, dez/2014-jan 2005, p. 97-99.

HOUAISS, A. Dicionário Eletrônico Houaiss. Rio de Janeiro: Objetiva, versão 1.0.1 [CD ROM], 2001).

ISKANDAR MALAYSIA: City of the Future. Disponível em: $<<$ http:/ /lankasia.com/

content/iskandar-malaysia-city-future>>. Acesso em 25 outubro 2017.

LAMBERT, Guy. Le maquettes d'architecture. Publications récents. État de la récherche. Archiscopie, 2e série, p. 91-96, 2016.

LIBERATI, Anna Maria. La rappresentazione di Roma antica nel plastico di Gismondi del Museo della Civilà Romana a Roma. Cahier de la MRSH, n. 33, p. 243-22, junho 2003.

MALIGORNE, Y., CHEVET, P., FERRETTE, R. Deux maquettes architecturales récemment découvertes à Rennes. Latomus, n. 69, 2010, p. 99-126.

PASQUALINI, Anna. L'antiquaria di gesso: passato e futuro del Museo della Civiltà romana all'Eur. Mediterraneo Antico, v. ix, n. 2, 2006, p. 1-16.

Paul Bigot: un normande à Rome. Disponível em: $<<$ https://www.unicaen.fr>>. Acesso em 26 outubro 2017.

ROYO, Manuel. Une nouveauté du xxe siècle? Maquettes de Rome et perception «paysagère » de l'histoire. Histoire de l'art, n. 65, out 2009, p. 8.

ROZESTRATEN, Artur Simões. Estudo sobre a história dos modelos arquitetônicos na Antiguidade: origem e características das primeiras maquetes de arquiteto. São Paulo: USP, 2003. 285p. Dissertação (Mestrado em Arquitetura e Urbanismo). Faculdade de Arquitetura e Urbanismo, Universidade de São Paulo. 